\title{
In memoriam: Prof. Dr. Edwaldo Eduardo Camargo (1938-2016)
}

\author{
Anneliese Fischer Thom ${ }^{1}$
}

Published online: 18 May 2016

(C) Springer-Verlag Berlin Heidelberg 2016

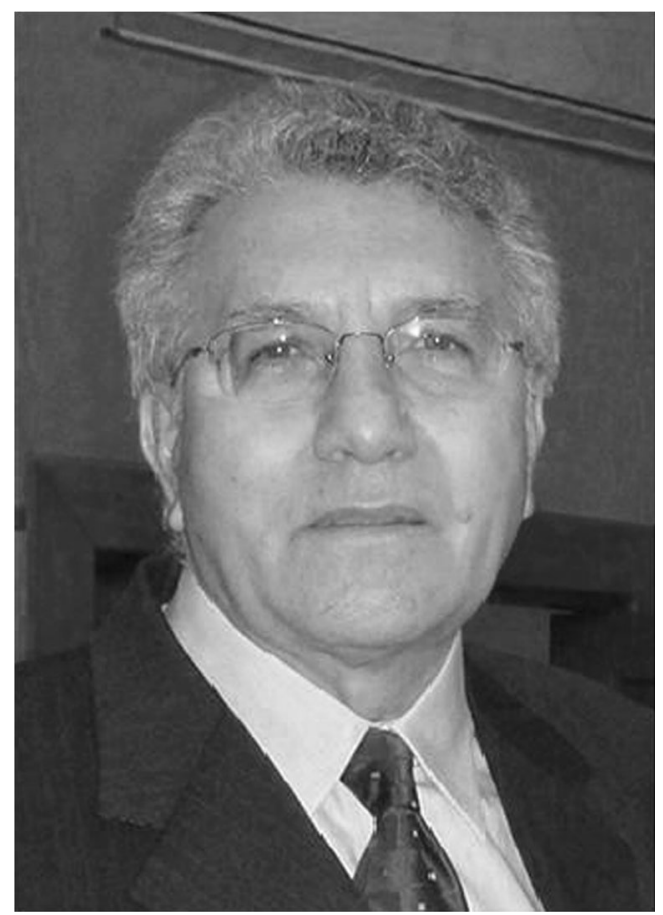

Prof. Dr. Edwaldo Eduardo Camargo, member of the Editorial Board of EJNMMI and one of the most distinguished Nuclear Medicine physicians of Latin America, died March 4th, at the age of 78 years, in São Paulo, Brazil.

Anneliese Fischer Thom

fthom@uol.com.br

1 Hospital Israelita Albert Einstein, São Paulo, SP, Brazil

Dr. Camargo graduated in Medicine at the University of São Paulo (USP) in 1966 and received his degree of Doctor in Medicine in 1971 at the same university. In 1973 he went to Johns Hopkins University in Baltimore, USA, for his fellowship in Nuclear Medicine under the prestigious direction of Prof. Henry Wagner. After conclusion, he was invited to stay at Johns Hopkins in Wagner's division, where he became successively Assistant Professor of Radiology, Clinical Director of the Division of Nuclear Medicine and Associate Professor of Radiology.

In 1982 Dr. Camargo came back to Brazil to take the position of Head of the Nuclear Medicine Division of USP and of the same division of the Univeristy's Heart Institute (Instituto do Coração, InCor). He made a short return of 3 years (19881991) to Hopkins University, as Associate Director of Radiology and again as Clinical Director of the Division of Nuclear Medicine.

In 1991 he was nominated Head of the Department of Radiology of the State University of Campinas (UNICAMP) and occupied this position until his retirement. In addition, he became Director of the Nuclear Medicine Department of Hospital Sirio-Libanês, in São Paulo, where he installed the first PET/CT equipment in South America.

A passionate teacher, Prof. Camargo had inherited the didactic qualities of his master Prof. Henry Wagner. He created the two main Nuclear Medicine residencies in Brazil, namely at USP and at UNICAMP and was responsible for the training and graduation of a host of young specialists, in Brazil as well as in the United States. He wrote over 35 book chapters, over 380 published papers and won 15 research prizes.

As president of the Brazilian Society of Nuclear Medicine (SBMN) for two consecutive periods (1992-1996), and also as president of the Latin American Association of Nuclear 
Medicine Societies (ALASBIMN, 1996-1997,) he exercised a strong political influence in favour of the development of the specialty in South America and established contacts with the sister societies of countries in Europe, North America, and Asia.
Prof. Camargo is missed by his colleagues, friends, and his many pupils and will ever be remembered for his unique contribution to Nuclear Medicine in his native country, his continent, and beyond. 